\title{
Features of the perception of information in the texts of mechanical engineering topics on the non-native language
}

\author{
Rafail Tazapchiyan ${ }^{1, *}$ and Elena Shapovalova ${ }^{1}$ \\ ${ }^{1}$ Don State Technical University, Gagarina square, 1, Rostov-on-Don, 344003, Russia
}

\begin{abstract}
In the present article described the way of obtaining of a new professionally valuable information by working with a text dedicated to the development of agricultural engineering is considered as one of the most effective ways to improve professional qualifications in the postgraduate period. The purpose of present article is to define and briefly describe the factors that provide the effective perception of the information of machinery engineering. Perception in this article is not limited to perceptual reception concept, but is understood as an active creative process targeted to satisfy the cognitive needs of an individual, both in obtaining a specialty and in the course of practical activity. To solve this goal, the authors clarified the concept of "text" as a set of units of different language levels transmitting information that has a heterogeneous nature, and criteria of the effectiveness of the processes of textual data perception, which in this case comes down to the choice of the recipient of an adequate communicative strategy or information processing. The strategy is interpreted as an important and effective mechanism for organizing speech behavior, which makes it necessary to describe its main characteristics and stages of formation.
\end{abstract}

\section{Introduction}

Mechanical engineering like any other industry, is in the process of constant development. This is facilitated by both the growth of new technologies, and expansion of annual business contacts with engineering industry specialists from diverse countries and multi-language communities. Professionally valuable information is the subject of exchange during such contacts, which may consist of international seminars, symposiums or popular online conferences.

With the presence and rapid development of multimedia technologies, one of the most important and most accessible sources of professional information is the text created by means of natural language.

It must be said that reading professional literature occupies a special place in professional training in the course of studying at a university. Professional training as a system of pedagogical activities takes from 80 to 90 percent of the study time and thus

\footnotetext{
* Corresponding author: rafail.tazapchiyan@mail.ru
} 
contributes to the formation of students' readiness to work in the field of their chosen specialty. Such training supposes the acquisition of significant volumes of scientific knowledge by students. One of the ways to obtain scientific knowledge is reading of specialized literature.

In the postgraduate period, such reading plays a primary role in the processes associated with the professional development of a specialist, as well as associated with the implementation of concept of currently popular continuing education. Traditionally is believed that for about $70 \%$ of post-graduate specialists, the use of a foreign language is limited to reading literature on their specific subject. Several researches have also shown that the use of foreign language serves the following purposes:

1) familiarization with publications on a specific topic to identify the main trends;

2) scientific research in a specific area;

3) patent search, when the data on filing an application or obtaining a similar patent or implementation of a similar development by other persons is checked;

4) study of new device designs or description of the main parameters of a new technology;

5) study of accompanying documentation for foreign-made equipment.

Considering the amount of information dedicated to the development of the machinarybuilding field, a specialist is necessarily faced with the task of optimizing his reading activity. In other words, we are talking about choosing a receptive strategy that will ensure the perception of significant amounts of data. The main elements of such strategies consist on orientation in the text space, search for data that is personal for the recipient (or of professional interest to him), processing of the obtained information which later becomes a part of the recipient's conceptual system, and therefore the basis for building a new strategy when solving similar tasks in the future [1].

While recognizing the possibilities of these strategies for the perception of professional information to optimize the process of obtaining new data, it should be noted that receptive strategies are quite flexible in their nature. In addition to a whole motivational system of prompting a mechanical engineer to start reading a text in his specialty, concretizing its goals and thus having a critical impact on the specifics of the strategy being formed, the text space itself has a significant impact on it $[2,3]$.

The purpose of this article is to identify and briefly describe the textual factors that provide the formation and possible correction of receptive strategies and, therefore the effective perception of information on machine-building topics set forth in a scientific and professional text in a language that is not native to the recipient.

\section{Materials and methods}

Our research was based on the professional texts published in specialized journals, and on the resources of Internet related to the engineering industry. These texts are targeted to the analysis of such problems of the current state of agricultural machinery as the scientific analysis of indicators of the provision of agricultural machinery with agricultural organizations, as well as the specification of the agricultural machinery market and its features. The information contained in the Russian version of the text, was subjected to linguistic observation and description by highlighting its main structural elements and attributing these elements to plainly communicative or thematic plan of the text, which made it possible to highlight and describe the corresponding structures of the texts of articles [4]. 


\section{Results}

The above tasks included a possible description of the process of informational perception. It was important to us that procedure of processing of engineering information coming from the text, is characterized not so much by the involvement of already known knowledge and methods for realizing the goal of the activity, but by the focus on understanding the grounds for a potential or perfect action [5, 6]. In our opinion, such a position allows a specialist reading a text in his specialty to penetrate deeply into the content of the source, and reflexively concern his actions to a greater extent.

When clarifying the factors influencing the formation and possible correction of the communicative receptive strategy, we proceeded from the fact that any recipient capable to organize correctly his own speech behavior does not as much neutralize the influence of the external environment such a professional text, as actively and purposely acting in this environment. In this case, the recipient uses these environmental parameters to obtain a useful result for himself. This means that his receptive activity is undergoing the following significant change: from a system with unlimited number of degrees of freedom, it turns into a system with the only degree of freedom at the moment.

Van Dake speaks more specifically about this. His point of view comes to the following conclusion: strategies in general terms are a characteristic of the cognitive communication plan that controls the optimal solution of a system of problems in a flexible and locally controlled way.

The ability of an individual to form and follow communication strategies is explained by a number of reasons. In first place, such strategies are directly related to the processes of preliminary planning of their own speech behavior, when a specialist is faced with several options for solving the task assigned to him, and chooses one of them. In second place, communication strategies are flexible because of their hypothetical and probabilistic nature. Due to this, at each given step the recipient takes into account both the consequences of previous and future steps. In this context, the strategies we describe can act in conditions of incomplete information and combine deductive and inductive methods of processing information coming from the text [7].

The interpretation of the communicative act presented in this article describing the perception of textual information, is correlated with the theory of decision making. Decision making is a special kind of human activity designed to help find the best alternative in a situation when different properties of objects are compared. This process goes through several stages. These include the formulation of the problem, the formation of options for its solution and the choice of the best of them. This scheme reflects the objective difficulties arising in the implementation of purposeful human activity - the need to make the correct decision in a situation of uncertainty. Uncertainty is a characteristic feature of tasks related to cognitive processes. The source of this uncertainty is two circumstances. The first of them is associated with the incompleteness of information that comes from the environment. The second has to do with the peculiarities of information processing by a person: the number of criteria taken into account when assigning an object to a particular class, preference for a sequential data processing process, etc. [8].

As you can see, the common place for the processes of forming an activity strategy (in our case, receptive) and the decision-making process is the resolution of the situation with the choice of one of the options for the implementation of the action. 


\section{Discussion}

To concretize the specifics of the factors that ensure the effective perception of information, subordinate to the action of the communicative strategy, we define the concept of "text" and clarify what we mean by the effectiveness of the process of perception of information.

When analyzing the concept of "text", we will base on the fact that this product of human communicative activity is a sequence of sign units, connected by a semantic link that meets the requirements of integrity and coherence. However, in order to achieve our set goal, a special interpretation of this concept is required. Regarding this, an understanding of a text as complex, multi-level unit of communication defined by extremely heterogeneous nature of its consistent information, will represent a special interest [9].

We suggest that especially the aforementioned heterogeneity of textual information allows the recipient to navigate in the text space, to select data according to the level of his personal interest (in our case, professional interest), and therefore to improve his professional level.

As indicated above, since the text has multi-level feature, then the interpretation of the phenomena of heterogeneity of its context can be extremely variable $[10,11]$.

The first level for us will be linguistic, when the so-called registers of speech are differentiated according to the specifics of their linguistic organization and therefore, to the possibility or non-possibility of their participation in texts of a particular type. These types include: pictorial-narrative, pictorial-descriptive, informative-narrative, informativedescriptive and others.

In our further reasoning, we note that the heterogeneity of textual information is primarily manifested at the level of its plainly substantive characteristics, since the basis of any text is thematic information. To a certain extent, the disclosure of the topic is the primary reason for the creation of a text as a unit of communication.

The problem of "theme" is one of the most developed in modern science. There are many scientific definitions of this concept, describing the topic from different positions. For the purposes of our analysis, the following is the most important: first, applying a certain amount of knowledge about the world, this topic belongs to extralinguistic categories; and second, since reality is interpreted as something that really exists and develops, and also contains the results of its own action and development, it determines the possibility for a topic to be revealed through a variety of means and methods. This variety may apply both at the extent of several texts, or within one single text. One of the most effective ways to describe the process of the development of a topic, in our opinion is to present the text as a combination of the main topic from the information source, and a set of subtopics describing its various aspects. Thus, the thematic structure of a text in the specialty is being formed by taking into account the features that help specialist to correctly build his own receptive strategy, and therefore to regulate the process of perception of professionally valuable data that meets his cognitive needs [12].

There is another type of text structure, which is organized by the correlation of logicalsemantic and intentional division of the text space. This hierarchy is based on the dichotomy of the main and additional (secondary) communicative intention of the author of the text. As a result, the macrostructure of a text in a specialty is represented by a hierarchy of different-order semantic blocks, or predication. Predication of the first order includes linguistic units that convey the most important information in the entire text. Predications of the next order (second, third, etc.) transmit less important information. The goal of such predications is to provide the details of the data supplying the main thesis, to complete these details or to set forth argumentation [13].

We consider necessary to note that the information conveyed by non-first-order predications, is complementary or excessive to some extent. However, its importance for 
the perception of the data of the entire message can hardly be overestimated, since such information allows the recipient to understand more deeply its main thesis.

Let us give an example of dividing a text into semantic blocks, or predications [14, 15].

"The growing gap between the retirement of combines that have exhausted their technical resource and the arrival of new machines presents the agro-industrial complex with a problem known as the "Problem 2006". Its essence lies in the fact that in a few years there will be an acute shortage of equipment necessary for harvesting grain crops within an acceptable time frame. According to experts, approximately $30 \%$ of the cultivated area will remain unharvested. In addition, over the past few years, the Ministry of Agriculture of the Russian Federation has published data on grain losses in the amount exceeding $\$ 1$ billion every autumn. This is largely due to the use of combines that have exhausted their resource and have not received the proper level of service."

This text outlines the analysis of the problems and prospects for the development of domestic agricultural machinary building, based on the example of one of the largest machine-building enterprises in the country "Rostselmash". In this given fragment of the text, the main speech intention of the author and, accordingly the first- order predication is the message about the lack of coordination of the elimination of the old agricultural machinery park and the processes of its renewal. This lack of coordination in the future may lead to serious problems in the industry. Second-order predication clarifies the first predication. The goal of third-order predication is to explain the reasons for the current condition of the industry.

Let us demonstrate this position graphically, indicating the rating of predication, the communicative function performed by this predication, and illustrating it directly with text stanzas.

Table 1. Predication rating Text fragment Communicative.

\begin{tabular}{|l|l|c|}
\hline Predication rating & \multicolumn{1}{|c|}{ Text fragment } & $\begin{array}{c}\text { Function (author's } \\
\text { intention) }\end{array}$ \\
\hline $\begin{array}{l}\text { Predication of the 1st } \\
\text { level }\end{array}$ & $\begin{array}{l}\text { "... the essence is that in a few years } \\
\text { there will be an acute shortage of } \\
\text { equipment necessary for harvesting } \\
\text { grain crops within an acceptable time } \\
\text { frame." }\end{array}$ & The main thesis \\
\hline 2nd level predication & $\begin{array}{l}\text { "According to experts, approximately } \\
30 \% \text { of the cultivated area will remain } \\
\text { unharvested. In addition, over the past } \\
\text { years, the Ministry of Agriculture of the } \\
\text { Russian Federation publishes data on } \\
\text { grain losses in excess of \$ billion } \\
\text { every autumn". }\end{array}$ & clarification \\
\hline Predication of the & $\begin{array}{l}\text { "This is largely due to the use of } \\
\text { combines that have exhausted their } \\
\text { resource and have not received the } \\
\text { proper level of service". }\end{array}$ & Argumentation \\
\hline
\end{tabular}

\section{Conclusion}

The results of our analysis of theoretical sources and authentic texts on machinery build topics, allow us to draw practical conclusions. The process of perceiving data of professional interest which is subject to the communication strategy chosen by the recipient, is distinguished both by a higher speed of information processing and by a special completeness and accuracy of its understanding. The effective creation of such strategy and 
its possible correction is actual in those cases, where the specifics of the source structure responsible for the informational organization are taken into account. Such structures are presented by us in two aspects: thematic- organizing the content of the statement, and functional-structuring the data of the text according to the level of relevance to the communicative intention. This strategically planned perception of given texts concerning machinery-building topics in a foreign language to the recipient, will make it less chaotic and more productive.

\section{References}

1. S. Wallot, New ideas of Psychology 42, 221-228 (2016)

2. Jing Sun, Qing Yu, Fayuan Chu, Microprocessors and Microsystems 80, 103578 (2020)

3. R.M. Tazapchiyan, M.V. Ereshchenko, E.Y Shapovalov, T.D. Rogacheva, The succes criterion of a communicative act 5(3.6), 651-656 (2018)

4. Lee McCallum, Studies in Corpus Linguistics English for Specific Purposes 62, 43-45 (2020)

5. Ferdi Akın, Özlem Koray, Koray Tavukçu, Procedia - Social and Behavioral Sciences 174, 2444-2451 (2015)

6. A. Klyoster, G. Galich, Procedia - Social and Behavioral Sciences 206, 56-61 (2015)

7. N.Riemer, Language \& Communication 64, 38-52 (2019)

8. I. Boux, R. Tomasello, F. Pulvermüller, Cortex2 135, 127-145 (2020)

9. S. Burbekova, A. Nurzhanova, Procedia - Social and Behavioral Sciences 136, 119-123 (2014)

10. I. Fytilakos, Ecological Informatics 61, 101203 (2020)

11. K. Erhard, F. Kessler, M. Lotze, Neurolmage, 15-23 (2014)

12. Cecil Eng Huang Chua, Veda C. Storey, Mala Kaul, Decision Support Systems 127, 113142 (2019)

13. Mamdouh Farouk, Cognitive Systems Research 63, 1-10 (2020)

14. V. Kumar Jain, Sh. Kumar, S. Lawrence Fernandes, Journal of Computational Science 21, 316-326 (2017).

15. M. Carnevale, D. Luna, D. Lerman, International Journal of Research in Marketing 34(2), 572-591 (2017) 